\title{
A mittanian-style cylinder seal from tel burna antónio de freitas
}

\begin{abstract}
Cylinder seals were ubiquitous in all Near Eastern cultures from Mesopotamia to the Levant and Anatolia. The first seals appear as early as the 4th millennium BCE and were used as pendants representing feminine and masculine sexual organs. ${ }^{1}$ Later, cylinder seals were engraved with figures and writing symbols and used for other purposes, very often to produce an engraving or an inscription on a clay tablet. Thus, cylinder seal production increased in parallel with the writing-in-clay culture. They were often used to mark ownership, and probably for this reason they were also used as amulets, as protectors of the property. ${ }^{2}$ During the Ur III period, cylinder seals played a significant role within the administrative notarial system as they were used by notaries to seal documents to confirm their contents and the participants of a contract would have sealed the documents in order to authorize the acceptance of the conditions, or simply demonstrate their ownership of an inventory. In some cases, the seals were also used to identify envelopes. The relevance of cylinder seals in ancient Near Eastern cultures was of such significance that a prolific industry of production was developed. During the Late Bronze Age, the Mitannian Empire became a substantial producer of cylinder seals, with some cities continuing to produce seals even after they had fallen to the Kingdom of Hatti. On account of this, the trade of seals from Mitanni to the southern Levant during the Late Bronze Age was extensive. ${ }^{3}$
\end{abstract}

Volume 3 Issue 6 - 2018

\section{Chris McKinny, Itzick Shai}

Department of historical geography and archaeology, Bar llan University, Israel

Correspondence: Chris McKinny, Department of historical geography and archaeology, Bar llan University, Israel, Email chrismckenny@gmail.com

Received: July 24, 20I8 | Published: November 26, 2018

\section{Introduction}

\section{Tel burna}

Tel Burna is located in the Shephelah of southern Israel along the northern banks of Nahal Guvrin (Figure 1). According to archaeological survey, it seems that the site was established in the
Early Bronze Age II, and settled intensively in the Middle Bronze Age, Late Bronze Age and Iron Age with more scarce activity during the Persian and Byzantine periods. ${ }^{4,5}$ The survey results have been largely corroborated by the excavations which indicate that the Late Bronze Age was one of the two periods (along with the Iron II) in which the settlement at Tel Burna reached its peak. ${ }^{6}$

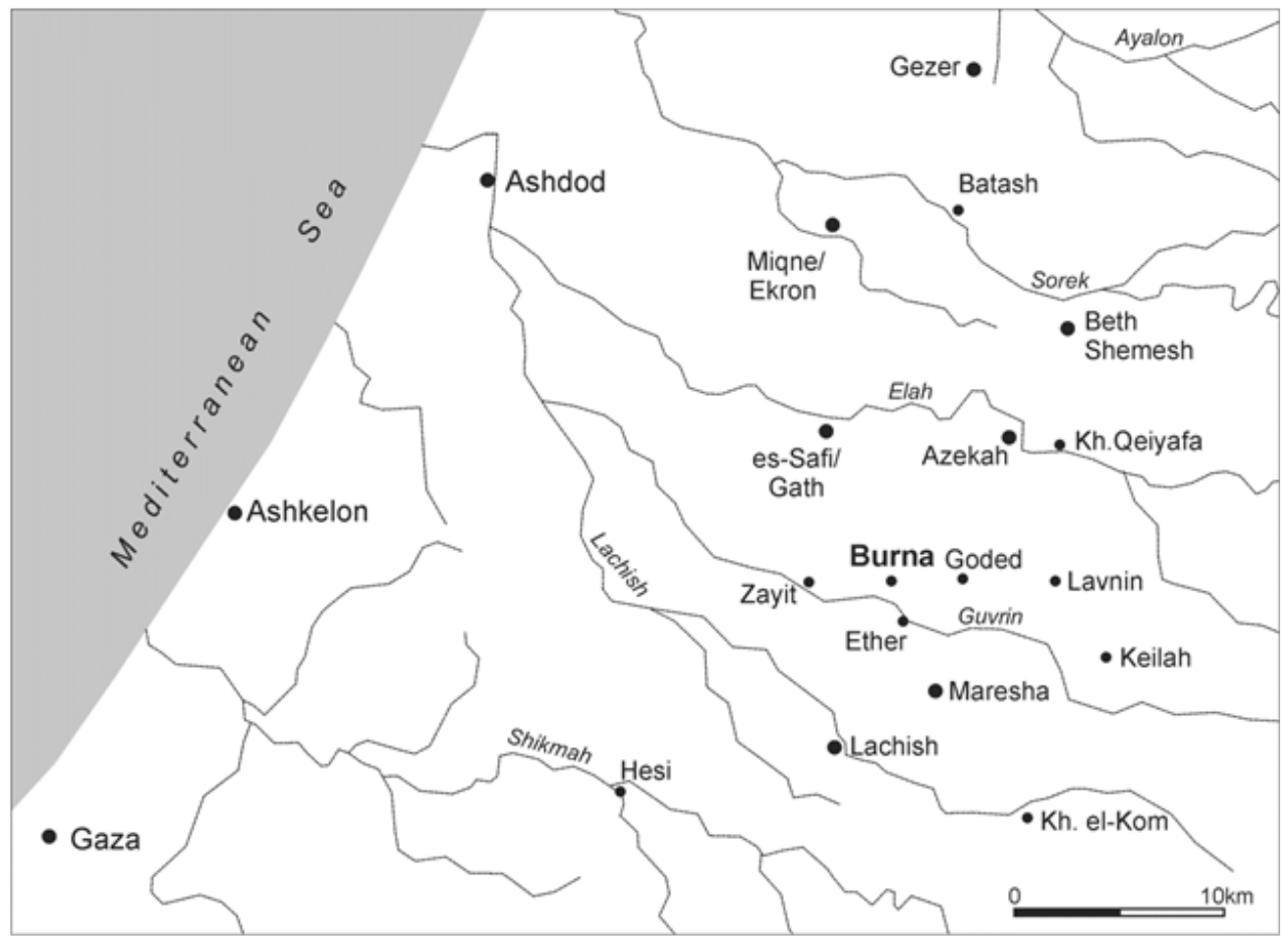

Figure I Location of Tel Burna on the bank of Nahal Guvrin. 


\section{Archaeological context}

Since 2011, excavations have been carried out on a platform (Area B1-c. 40x100m; Figure 2) located below and to the west of the summit of Tel Burna. Before we began excavating this platform, intensive archaeological survey seemed to indicate that this area was settled only in the Late Bronze Age due to the high quantities of Late Bronze Age sherds and the absence of other periods. ${ }^{4,5}$ Already in the first excavation season this determination was shown to be accurate, as we uncovered an extensive Late Bronze layer that was primarily founded on the bedrock directly beneath the top soil. After seven seasons (2011-2017), the excavations have revealed the remains of a large cultic structure with a large courtyard. ${ }^{6,7}$ The exact layout of the structure remains unclear with sections of the building suffering from severe erosion. The western wall of Building 29305 is preserved to a length of 17 meters. While our interpretation remains tentative, it seems that the building is bounded on the north by a poorly preserved wall (W734007) and on the east and south by walls (W63405 and W63408) that appear to form a corner near the base of the tell's summit. Within the building, we found evidence of two tanurs (ovens) (L53403 and L29104), which may indicative that it was a large open air courtyard.

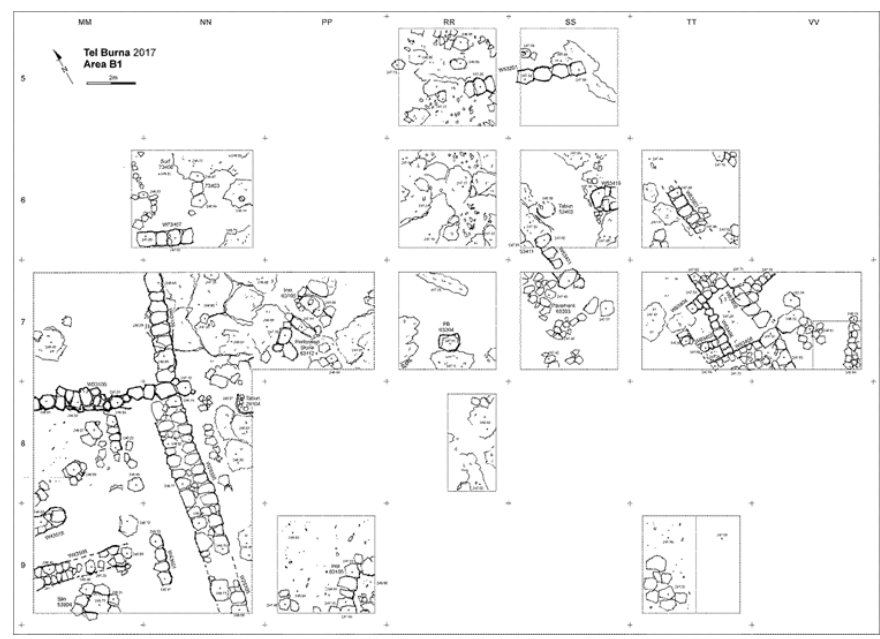

Figure 2 Archaeological excavations have been carried out on a platform, west of the summit of Tel Burna.

The most well-preserved and significant section of Building 29305 is located on a flat bedrock courtyard (L33211). This courtyard is demarcated on the west by the western wall of the building and on the east by a tabun (L29104) and what seems to be three standing stones including a large rectangular piece of chalk (L63112-measuring c. 1 meter longx $30 \mathrm{~cm}$ widex $70 \mathrm{~cm}$ tall) with a perforated hole through its center. In addition, two very large Cypriot pithoi of the wavy-band style were found embedded on the southeastern side of the courtyard (Shai et al. in preparation). Besides there being a high quantity of bones $^{8}$ and restorable locally made domestic vessels, the finds in this courtyard point to a clear cultic affiliation of the space. Within the courtyard, we found numerous locally made chalices and goblets figures $6-7 ;{ }^{6}$ locally made figurines figure $8.4 ;{ }^{6}$ figures 4,6$) ;{ }^{9}$ Cypriot zoomorphic vessels and Mycenaean figurines figure 6.1-3; figure 5); ${ }^{9}$ a unique Cypriot three-cupped votive vessel, which was found in situ on top of a flat rock in a crevice of the bedrock figure $7.11 ; 9$ an Egyptian scarab figure $6.12 ; 6$ and a Mittani glyptic style cylinder seal (Figure 2) the last of which is the subject of this paper. While other cultic objects were found in different sections of the building (e.g., a Revadim-style plaque figurine-figure $8.7 ; 6$ figure $3 ;{ }^{9}$ and two ceramic masks, ${ }^{7}$ the high concentration of cultic and prestige-related objects on the bedrock courtyard seems to indicate that courtyard L33211 was the focal point of cultic activity within Building 29305.

\section{A mittani style cylinder seal}

During the 2012 season at Tel Burna, a cylinder seal was found in Area B1. The seal is made of steatite (see below for spectrographic analysis). It measures $20 \mathrm{~mm}$ in height by $7 \mathrm{~mm}$ diameter wide (Figure 3). It shows a procession of running lions moving towards the right. The procession of animals was a common motif on seals from Kamid el-Loz. Even though there are no examples of seals with such a procession of lions, the use of the steatite and the elongated figures of lions have clear parallels with some of the cylinder seals found in Kamid el-Loz. The presence of two circle border lines on the top and bottom of the seal point towards a Mitannian influence. ${ }^{10}$ One should also note the un-common vertical design. ${ }^{11}$ The lions are also associated to the goddess Astarte or Asherah who are often depicted as a naked female standing on the backs of lions. ${ }^{12}$ However, the lion is also sometimes associated with Baal/Hadad, which is the Northwest Semitic name for the Sumerian storm-god Ishkur, and is usually depicted as a 'roaring lion'. ${ }^{12}$ On the other hand, the lion is also an attendant of the Storm-God ${ }^{12}$ in general and particularly, the Akkadian Adad or Hadad is usually accompanied by a roaring lion. ${ }^{12}$

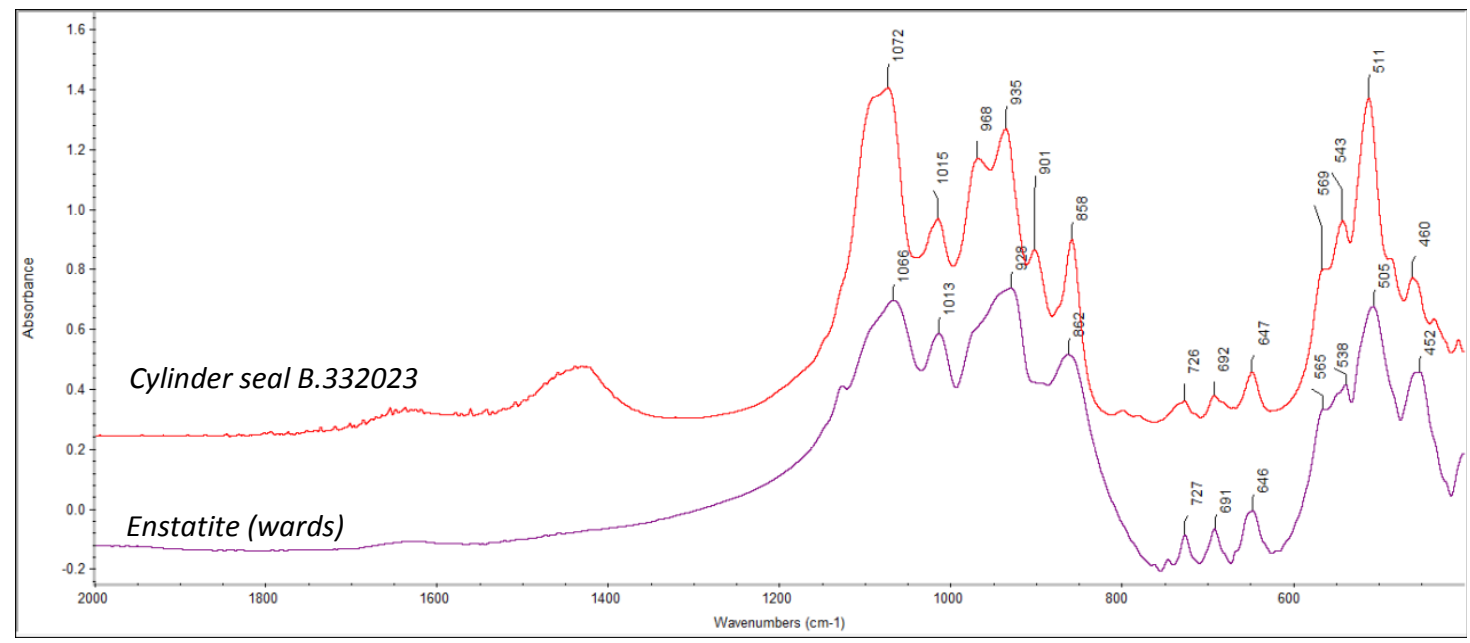

Figure 3 FTIR spectra of Tel Burna cylinder seal B. 332023 and the mineral enstatite. 


\section{Fourier transform infra-red spectroscopy analysis}

The seal was first analyzed using Fourier Transform Infra-red Spectroscopy (FTIR), in order to identify its mineralogy. A hidden surface of the seal was carefully scratched to obtain ca. $0.2 \mathrm{mg}$ of sample. Spectra were obtained by placing the resultant powder into an agate mortar and pestle, grinding and mixing with $\mathrm{KBr}$ (IR-grade) and pressing into a pellet using a hand press. Spectra were collected between 4000 and $400 \mathrm{~cm}^{-1}$ at $4 \mathrm{~cm}^{-1}$ resolution for 32 scans using a Thermo iS5 portable spectrometer. The advantage of this method lies in its ability to provide useful information on the mineral phase present - while only using a very small sample, within a matter of minutes. The FTIR spectrum (Figure 4) obtained from the seal along with the spectrum of standard enstatie mineral (wards). It is clearly seen that the two spectra are almost identical, identifying the seal to be made of enstatite $\left(\mathrm{MgSiO}_{3}\right)$. This mineral is the magnesium end member of the pyroxene-silicate series, and is a common rockforming mineral in igneous and metamorphic rocks. It can appear in various grades of white, green, grey yellow or brown (depending on exact composition). By mass, enstatite is approximately $60 \%$ silica $\left(\mathrm{SiO}_{2}\right)$ and $40 \%$ magnesia $(\mathrm{MgO})$ and may contain minor quantities of other oxides such as $\mathrm{CaO}$ or $\mathrm{Al}_{2} \mathrm{O}_{3}$ and trace to minor $\mathrm{Fe}-\mathrm{Cr}$ oxides.
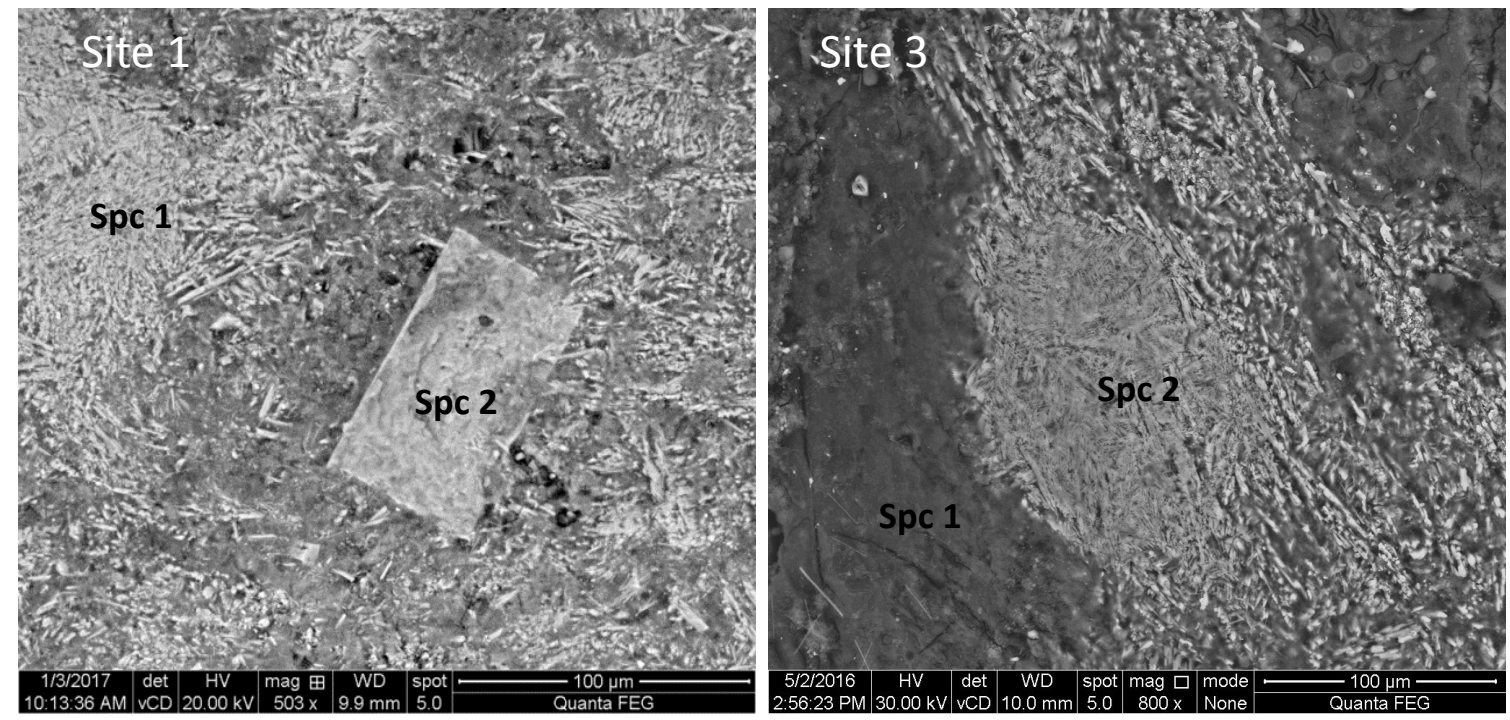

Figure 4 Scanning electron microscope images, showing areas of the sample at which metallic luster was observed under optical microscopy. Noted are points of EDS analysis (see table below).

Enstatite can be synthetically formed by firing of steatite-a hydrous magnesium silicate, naturally occurring rock (also known as soapstone) made up primarily of the mineral talc. Steatite is soft and therefore easily carved and shaped, and can be also made into a paste to be used in a mold (usually by mixing with other constituents). Upon heating, steatite decomposes and recrystallizes into the more hard and durable form of enstatite. Heat-treated steatite was used from at least as early as the $7^{\text {th }}$ millennium BCE for the production, of small objects such as beads, scarabs and seals. The use of glazing applied onto steatite/enstatie is also known and documented. Under optical microscopy, some surface areas of the seal show metallic copper/ gold like luster (which raised the assumption that it might have been covered/gilded in antiquity). The sample was further studied using an environmental SEM equipped with an Oxford EDS analyzer, without further treatment (no surface coating) and was analyzed at low vacuum mode (Figure 4). Results show that the general matrix of the sample is indeed composed of high percentage of silica (an average of ca. $53 \%$ ) whereas the average magnesia content is somewhat lower than expected (see Table 1). However, other constituents were also identified, including minor concentrations of alumina $\left(\mathrm{Al}_{2} \mathrm{O}_{3}\right)$, lime $(\mathrm{CaO})$, potash $\left(\mathrm{K}_{2} \mathrm{O}\right)$, soda $\left(\mathrm{Na}_{2} \mathrm{O}\right)$ and iron, chromium and copper oxides. In some specific points of analysis (not shown in images, Table 1), high $\mathrm{Cr}-\mathrm{Fe}$ oxides content was measured-which is well known for steatite/enstatite minerals.

Table I Results of SEM-EDS analysis, elements detected represented as oxides and normalized.

\begin{tabular}{lllllllllllll}
\hline & $\mathrm{Na}_{2} \mathbf{O}$ & $\mathbf{M g O}$ & $\mathbf{A l}_{2} \mathbf{O}_{3}$ & $\mathbf{S i O}_{2}$ & $\mathbf{C l}$ & $\mathbf{K}_{2} \mathbf{O}$ & $\mathbf{C a O}$ & $\mathbf{C r}_{2} \mathbf{O}_{3}$ & $\mathbf{F e}_{2} \mathbf{O} 3$ & $\mathbf{C u O}$ & $\mathbf{S U M}$ \\
\hline Site I: spcl & Matrix with needles & 1.7 & 14.7 & 4.8 & 55.9 & 0.9 & 2.6 & 7.9 & & 6.9 & 4.6 & 100 \\
Site I: spc2 & Matrix with square crystal & 1.5 & 13.8 & 4.8 & 58 & 0.9 & 2 & 8 & & 6.3 & 4.7 & 100 \\
Site 3: spcl & Matrix & & 3 & 6.1 & 63.2 & 1.4 & 3 & 5.9 & & 10.4 & 7 & 100 \\
Site 3: spc2 & Matrix with needles & & 22.9 & 2.3 & 58.2 & 0.3 & 0.9 & 4.6 & & 3 & 7.8 & 100 \\
Site 2: spcl & Chromium inclusion & 1.7 & 7.4 & 7 & 28.3 & 0.4 & 1.4 & 4.6 & 28.9 & 17.8 & 2.5 & 100 \\
\hline
\end{tabular}

The relative low magnesia concentration on the one hand and the high concentration of other constituents (especially lime, alumina, potash and soda) on the other may indicate that a glazing layer was applied to the seal surface. Another option is that the seal was made by mixing steatite with other constituents to make a paste and then heated. Enstatite with a small amount of iron oxides (up to $12 \%$ ), like in the case of Burna seal, may exhibit a metallic sheen/luster of a bronze-like color, called bronzite (Figure 4). This phenomenon is 
known to happen upon weathering of the iron oxides which results in the separation of iron as very thin films along the cleavage/cracks of the mineral. Results show that the seal is made of enstatite, likely to be made by heating of steatite. Although copper was detected in the seal matrix, in considerable concentrations, traces of metallic copper or gold where not observed. Thus, no evidence for gilding or the application of fine metallic copper surface was found. Copper is usually a pigment used in glazes, resulting in a range of light bluish colors. No remnants of such colors were observed. Whether a glaze was applied to the surface of the seal is impossible to tell without further studying the object by creating a section. ${ }^{13}$

\section{Conclusion}

Under microscopic inspection, the seal showed gleaming elements that we initially thought could have been due to the presence of gold or copper, but the spectrographic analysis showed that those elements are produced by bronzite. This seal was probably included in a necklace or bracelet and that it was most likely produced outside the land of Canaan, which is not surprising due to the international commercial activity that existed in the Levant during the Late Bronze Age. It was likely used as an amulet, perhaps associated with the cult of Astarte or Asherah, consort(s) of Baal. The presence of this seal in this specific building supports the interpretation that it was a public building and in combining this find with the various imported finds that were recovered within it. Thus, it reflects the eclectic nature of the inhabitants of this building.

\section{Acknowledgments}

None.

\section{Conflicts of interest}

Authors declare that there is no conflict of interest.

\section{References}

1. Collon D. First impressions: Cylinder Seals in the Ancient near East. 2nd revised edition, London: British Museum; 2005.
2. Greenfield TC, McKinny, Shai I. "I Can Count All My Bones": A Preliminary Report of the Late Bronze Faunal Remains from Area B1 at Tel Burna, Israel. In: Lev Tov J, Gilbert A, Hesse P, editors. The Wide Lens in Archaeology: Honoring Brian Hesse's Contributions to Anthropological Archaeology. Georgia: Lockwood Press; 2017.

3. Green ARW. The Storm-God in the Ancient Near East. Eisenbrauns, Indiana; 2003

4. Kühne, Salje. Kamid el-Loz, 15, Die Glyptik. Bonn; 1996.

5. Matthews DM. Principles of Composition in Near Eastern Glyptic of the Later Second Millennium B.C. Switzerland: University of Zurich; 1990.

6. Porada E. Why Cylinder Seals? Engraved Cylindrical Seal Stones of the Ancient Near East, Fourth to First Millennium B.C. The Art Bulletin. 1993;75(4):563-582.

7. Shai I. Two Late Bronze Age Ceramic Masks from Tel Burna, Israel. In: Angelika Berlejung, Judith E Filitz, editors. The Physicality of the Other Masks from the Ancient Near East and the Eastern Mediterranean (Orientalische Religionen in der Antike 27). Mohr Siebeck; 2018. p. 133-139.

8. Shai IC, McKinny, Uziel J. Late Bronze Age Cultic Activity in Ancient Canaan: A View from Tel Burna. Bulletin of the American Schools of Oriental Research. 2015;374:115-133.

9. Shai I, Uziel J. Addressing Survey Methodology in the Southern Levant: Applying Different Methods for the Survey of Tel Burna, Israel. Israel Exploration Journal. 2014;64(2):172-190.

10. Sharp CC, McKinny, Shai I. Late Bronze Age Figurines from Tel Burna. Strata: Bulletin of the Anglo-Israel Archaeological Society. 2015;33:6176.

11. Stuckey JH. The Great Goddesses of the Levant. JSSEA. 2003;30:127-157.

12. Uziel J, Shai I. The Settlement History of Tel Burna: Results of the Surface Survey. Tel Aviv. 2010;37(2):227-245.

13. Ziffer I, Jakoel E. A Cylinder Seal from Yehud. Israel Exploration Journal. 2017;67:1-13. 